\title{
Pulmonary and systemic arterial pressure in hyaline membrane disease
}

\author{
Jonathan R Skinner, Richard J Boys, Stewart Hunter, Edmund N Hey
}

\begin{abstract}
Systolic pulmonary arterial pressure was determined serially over the first 10 days of life in 33 babies with hyaline membrane disease by measuring the peak velocity of pansystolic tricuspid valve regurgitation, using Doppler ultrasound, and applying the Bernoulli equation. Results are presented in age groups 0-12, 13-36, 37-72, and 73-96 hours respectively. The incidence of tricuspid valve regurgitation was $92,97,80$, and $64 \%$ (falling to $35 \%$ by day 10 ) compared with $53,50,31$, and $0 \%$ in 17 healthy premature infants.

In comparing healthy babies with those with hyaline membrane disease, no allowance was made for right atrial pressure. The derived 'right ventricle to right atrial (RV-RA) pressure difference', was expressed as a ratio of systemic arterial (systolic) pressure. Over the first three days, this ratio fell much faster in the healthy babies. Values were $0 \cdot 78: 1,0.77: 1$, and $0.72: 1$ in babies with hyaline membrane disease and $0.87: 1,0.53: 1$, and $0.44: 1$ in healthy babies.
\end{abstract}

Ductal patency was prolonged in babies with hyaline membrane disease $(75 \%$ on day 4 compared with $6 \%$ in healthy babies). The incidence of bidirectional ductal flow, indicating balanced pulmonary and systemic arterial pressures, was $79,53,30$, and $20 \%$, and in healthy babies was $41 \%$ at $0-12$ hours and zero thereafter.

Pulmonary arterial pressure was then calculated by adding a right atrial pressure estimate of $5 \mathrm{~mm} \mathrm{Hg}$ to the RV-RA difference when the babies were ventilated. Babies of lower gestation had lower values. The pulmonary:systemic arterial pressure ratio showed considerable temporal variability, but fell with age and was raised by high mean airway pressure and pneumothorax (through a reduction in systemic pressure), and less noticeably by carbon dioxide tension. It did not correlate significantly with other indices of disease severity.

Hyaline membrane disease is associated with delayed postnatal circulatory adaptation characterised by pulmonary hypertension, systemic hypotension, and prolonged ductal patency.

Department of Paediatric Cardiology,

Freeman Hospital, Newcastle upon Tyne

Stewart Hunter

Correspondence to:

Dr Jonathan $R$ Skinner,

Department of Child Health,

Princess Mary

Maternity Hospital,

Mreat North Road,

Newcastle upon Tyne

NE2 3BD.

Accepted 8 November 1991 tension by direct catheter measurement in 11 unventilated babies. ${ }^{1}$ Chu et al, in their influen- tial paper entitled 'neonatal pulmonary ischaemia' 25 years go, showed that pulmonary blood flow, gas transfer, and clinical status were improved by an infusion of acetylcholine, and argued that pulmonary perfusion, rather than surfactant deficiency might be the primary underlying cause of hyaline membrane disease. ${ }^{2}$ It was only some years later that surfactant deficiency came to be accepted as the main cause. ${ }^{3}$ Since then the part played by pulmonary vascular tone and extrapulmonary shunting has received relatively little attention, and arguably less attention than it deserves.

Due to the invasive nature of cardiac catheterisation, serial direct measurements of pulmonary arterial pressure have never been possible, but new developments in Doppler ultrasound now make it possible to estimate pulmonary arterial pressure non-invasively. The most direct technique available utilises measurement of the maximal velocity of a regurgitant jet from the tricuspid valve with application of the Bernoulli equation. This method has been validated extensively against direct catheter measurements both in adults and children. ${ }^{4-8}$ In a previous report we showed that healthy neonates in the first three days of life commonly have tricuspid regurgitation measurable on Doppler echocardiography. ${ }^{9}$

The aim of the present study was to obtain serial measurements of pulmonary arterial pressure by non-invasive means in babies ventilated for hyaline membrane disease and to correlate results with the severity of the disease, blood gas status, and gestational age during the first 10 days of life.

\section{Subjects and methods}

The study group consisted of 33 ventilator dependent neonates diagnosed clinically and radiographically as having hyaline membrane disease in the two regional neonatal units in Newcastle. Babies were of 25-39 weeks' gestation (median 30.5). Birth weight was between $893 \mathrm{~g}$ and $3020 \mathrm{~g}$ (median 1651). Three babies died: at 12 hours, 9 days, and 11 days respectively. None of the babies received exogenous surfactant.

The results were compared with those obtained in the first 72 hours of life from 17 healthy premature neonates who were not ventilated, not oxygen dependent, and had no history of perinatal asphyxia. Birth weight in this group was between $1143 \mathrm{~g}$ and $2290 \mathrm{~g}$ (median 1608) and gestational age was between 28 and 35 weeks (median 32). Parental permission for serial study was obtained in all cases 
and ethical approval was granted by the district ethics committee.

\section{MEASUREMENT TECHNIQUE}

Examinations were performed by a single observer when the babies were clinically stable, starting during the first $\mathbf{2 4}$ hours of life, three or four times in the first five days of life, and intermittently until successful extubation. At the first examination normal cardiac anatomy was confirmed with cross sectional and pulsed Doppler echocardiography. At all examinations a detailed Doppler echocardiographic study was done using one of two Hewlett-Packard ultrasound machines. The maximal velocity of the jet of tricuspid regurgitation was measured, as previously described, using a blind $1.9 \mathrm{MHz}$ probe. ${ }^{9}$ Ductal patency was established, and flow velocities recorded, using a combination of cross sectional echocardiography, pulsed and continuous wave Doppler. Detailed clinical status was recorded and the arterial:alveolar (a:A) oxygen tension ratio was used as a measure of disease severity. ${ }^{10}$ Systolic blood pressure was determined by indwelling arterial line or Doppler sphygmomanometry.

\section{TRICUSPID REGURGITATION AND THE BERNOULLI EQUATION}

The Bernoulli equation is derived from fluid mechanics and relates the pressure drop between two chambers to the velocity of the fluid passing between them. ${ }^{11}$ The peak velocity of blood, measured using continuous wave Doppler, is converted into a pressure drop by application of the modified Bernoulli equation: $p=4 v^{2}$, where $\mathrm{p}$ is the pressure drop ( $\mathrm{mm} \mathrm{Hg}$ ) and $\mathrm{v}$ is the velocity of blood (metres/second). In the right heart, the drop in pressure from the right ventricle to the right atrium in systole can be assessed by applying the Bernoulli equation: right ventricular pressure-right atrial pressure $=4 \times(\text { tricuspid regurgitant jet velocity })^{2}$.

Systolic pulmonary arterial pressure is equal to right ventricular systolic pressure if there is no pulmonary stenosis. Hence systolic pulmonary arterial pressure is equal to the drop in pressure in systole between right ventricle and right atrium plus the right atrial pressure. In the healthy neonate, shortly after birth, right atrial pressure is close to zero. Therefore in these babies no allowance for right atrial pressure is necessary.
In the babies with hyaline membrane disease, changes in right atrial pressure are still small in comparison with arterial pressure changes, but a small allowance for right atrial pressure may be appropriate to allow fair comparison of our results with previous direct measurements of pulmonary arterial pressure and with concurrent systemic blood pressure. Two of the babies in this study had single central venous pressure measurements made: one measurement was $4 \mathrm{~mm} \mathrm{Hg}$ and the other $6 \mathrm{~mm} \mathrm{Hg}$. After reviewing all the available evidence, ${ }^{12}$ we decided to allow $5 \mathrm{~mm} \mathrm{Hg}$ for right atrial pressure in babies ventilated at the time of the examination when determining pulmonary arterial pressure. This allowance was made when presenting the results shown in figs 2 and 3 and tables 4 and 5. However, because this allowance can only be approximate, and to permit direct comparison between the ill and healthy babies, we have presented the actual observed pressure difference across the tricuspid valve in table 2 , and called this the 'right ventricle to right atrial (RV-RA) pressure difference'.

\section{DUCTAL FLOW}

The pattern of flow during the cardiac cycle was observed and recorded along with the peak left to right flow velocity. 91314 The pressure difference between the systemic and pulmonary circulations was also assessed, by estimating the pressure gradient across the arterial duct. ${ }^{13}$ is This was done by applying the Bernoulli equation to the maximal left to right flow velocity across the duct.

\section{Results}

INCIDENCE OF TRICUSPID REGURGITATION

The incidence of measurable tricuspid regurgitation (where the peak velocity is seen clearly) in the healthy preterm babies and the babies with hyaline membrane disease is shown in table 1. The incidence was significantly higher in babies with hyaline membrane disease throughout the first 72 hours. After this, none of the healthy babies was found to have measurable tricuspid regurgitation, and the incidence in babies with hyaline membrane disease began to fall, although it was possible to follow the course of pulmonary arterial pressure in half of the babies requiring oxygen for up to 10 days. The procedure was well tolerated by even the sickest babies as long

Table I Incidence of tricuspid regurgitation measurable on Doppler ultrasound in 33 babies with hyaline membrane disease and 17 healthy preterm babies

\begin{tabular}{|c|c|c|c|c|c|c|c|}
\hline \multirow{2}{*}{$\begin{array}{l}\text { Age range } \\
\text { (hours) }\end{array}$} & \multicolumn{4}{|c|}{ Infants with hyaline membrane disease } & \multicolumn{3}{|c|}{ Healthy preterm infants } \\
\hline & $\begin{array}{l}\text { Mean age } \\
\text { (hours) }\end{array}$ & No examined & No ventilated & $\begin{array}{l}\text { No }(\%) \text { in whom } \\
\text { tricuspid regurgitation } \\
\text { measurable }\end{array}$ & $\begin{array}{l}\text { Mean age } \\
\text { (hours) }\end{array}$ & No examined & $\begin{array}{l}\text { No }(\%) \text { in whom } \\
\text { tricuspid regurgitation } \\
\text { measurable }\end{array}$ \\
\hline $\begin{array}{l}0-12 \\
13-36 \\
37-72 \\
73-96 \\
97-144 \\
145-192 \\
193-240\end{array}$ & $\begin{array}{r}7 \\
23 \\
50 \\
84 \\
119 \\
169 \\
221\end{array}$ & $\begin{array}{l}13 \\
30 \\
30 \\
25 \\
28 \\
17 \\
19\end{array}$ & $\begin{array}{l}10 \\
26 \\
28 \\
25 \\
24 \\
12 \\
11\end{array}$ & $\begin{array}{l}12(92)^{*} \\
29(97)^{* * *} \\
24(80)^{* *} \\
16(64)^{* *} \\
16(57) \\
7(41) \\
11(58)\end{array}$ & $\begin{array}{r}6 \\
27 \\
44 \\
88\end{array}$ & $\begin{array}{l}15 \\
16 \\
16 \\
17\end{array}$ & $\begin{array}{l}8(53) \\
8(50) \\
5(31) \\
0\end{array}$ \\
\hline
\end{tabular}


as they were kept warm during the examination. On some occasions measurement of the peak velocity of tricuspid regurgitation was hampered by the presence of a pneumothorax, the small amounts of interposing air being impervious to ultrasound. In one baby, with a pneumothorax on day 1 , no measurements were obtainable despite some Doppler evidence of tricuspid regurgitation.

After day 6 (144 hours), fewer babies were examined because some were extubated and well. Therefore the values derived from those babies who were studied may not be descriptive of the group as a whole. If none of the babies with hyaline membrane disease who were well by 193-240 hours had measurable tricuspid regurgitation, then the true incidence of regurgitation at this time would be $35 \%$ (see table 1 ).

\section{RIGHT VENTRICULAR AND SYSTEMIC ARTERIAL PRESSURES}

Measurements of systemic blood pressure, and the RV-RA pressure difference are shown in table 2. Over the first 24 hours, systolic blood pressure rose by a mean of $7 \mathrm{~mm} \mathrm{Hg}$ in the healthy babies. A significant rise was not seen until day 4 in the ill babies.

The RV-RA pressure difference was similar in the two groups in the first 12 hours, but then fell rapidly in the healthy babies, and more slowly in the babies with hyaline membrane disease. A comparison between the ill and healthy babies is shown in fig 1 , where the RV-RA pressure difference is expressed as a ratio of systemic blood pressure.

\section{DUCTAL FLOW}

Ductal patency was prolonged in hyaline membrane disease. By day 4 all but one of the healthy premature babies had a closed duct, while in the diseased group it was still patent in 24 of $32(75 \%)$. Only two of these 24 babies (8\%) had a clinically audible ductal murmur.

\section{Flow patterns}

Bidirectional ductal flow, right to left in systole and left to right in diastole, is known to be associated with balanced pulmonary and systemic arterial pressures. ${ }^{13-15}$ The incidence of bidirectional flow was higher in the ill babies at all ages. The difference between the

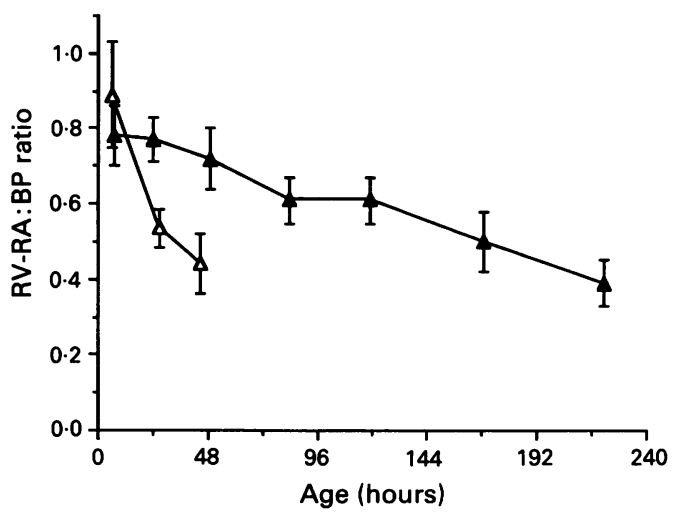

Figure 1 Right ventricle to right atrial pressure difference $(R V-R A)$ expressed as a ratio of systemic arterial pressure $(B P)$. Values are mean and $95 \%$ confidence limits for the mean. The closed triangles represent values from 33 babies with hyaline membrane disease and the open triangles are from 17 healthy preterm babies. (The proportion at each age who had measurable tricuspid regurgitation, allowing right ventricular pressure to be derived, are shown in table 1.)

groups was most noticeable at 13-36 hours when $53 \%$ of the babies with hyaline membrane disease had a patent duct with bidirectional flow, while all the healthy babies with a patent duct had pure left to right flow.

\section{Aorto-pulmonary pressure difference}

The derived maximal pressure difference is shown for each age group in table 3. Comparing babies with hyaline membrane disease with well babies, values are similar in the first 12 hours but become strikingly different after 12 hours. This confirms the rapid fall in pulmonary arterial pressure in relation to systemic pressure in healthy babies and a slower fall in babies with hyaline membrane disease.

COMPARISON OF DUCTAL FLOW PATTERNS WITH ARTERIAL PRESSURE RATIO

The pulmonary:systemic arterial pressure ratio was compared with concurrent ductal flow patterns. There were 42 examinations with bidirectional flow and measurable tricuspid regurgitation. With no allowance for right atrial pressure the mean ratio (and its standard deviation) was $0.87(0 \cdot 17): 1$. Allowing $5 \mathrm{~mm} \mathrm{Hg}$ for right atrial pressure in the ventilated babies the ratio was $0.97(0 \cdot 18): 1$. As the pressures can be expected to be approximately equal, this

Table 2 A comparison of systemic and right heart pressures in 33 babies with hyaline membrane disease and 17 healthy premature babies

\begin{tabular}{|c|c|c|c|c|c|c|c|c|c|}
\hline \multirow{2}{*}{$\begin{array}{l}\text { Age range } \\
\text { (hours) }\end{array}$} & \multicolumn{5}{|c|}{ Infants with hyaline membrane disease } & \multicolumn{4}{|c|}{ Healthy preterm infants } \\
\hline & $\begin{array}{l}\text { Mean age } \\
\text { (hours) }\end{array}$ & $\begin{array}{l}R V-R A \\
\text { difference } \\
(\text { mm } \mathrm{Hg})\end{array}$ & $\begin{array}{l}\text { Systemic } \\
\text { systolic BP } \\
\text { (mm Hg) }\end{array}$ & $\begin{array}{l}R V-R A: \\
\text { systolic } B P \\
\text { ratio }\end{array}$ & a:A ratio & $\begin{array}{l}\text { Mean age } \\
\text { (hours) }\end{array}$ & $\begin{array}{l}R V-R A \\
\text { difference } \\
(m m \mathrm{Hg})\end{array}$ & $\begin{array}{l}\text { Systemic } \\
\text { systolic BP } \\
\text { (mm Hg) }\end{array}$ & $\begin{array}{l}R V-R A: \\
\text { systolic } B P \\
\text { ratio }\end{array}$ \\
\hline $\begin{array}{l}0-12 \\
13-36 \\
37-72 \\
73-96 \\
97-144 \\
145-192 \\
193-240\end{array}$ & $\begin{array}{r}7 \\
23 \\
50 \\
84 \\
119 \\
169 \\
221\end{array}$ & $\begin{array}{l}38 \cdot 7(9 \cdot 5) \dagger \\
35 \cdot 9(7 \cdot 5)^{*} \\
35 \cdot 6(7 \cdot 6)^{*} \\
34.6(9 \cdot 1) \\
34.4(6 \cdot 1) \\
32 \cdot 6(4 \cdot 4) \\
25.9(5 \cdot 4)\end{array}$ & $\begin{array}{l}48 \cdot 8(6 \cdot 2) \dagger \\
47 \cdot 3(6 \cdot 8)^{* *} \\
49 \cdot 6(9 \cdot 5)^{* * *} \\
56 \cdot 2(9 \cdot 8) \\
56 \cdot 2(8 \cdot 7) \\
57 \cdot 2(11 \cdot 7) \\
65 \cdot 6(10 \cdot 6)\end{array}$ & $\begin{array}{l}0 \cdot 78: 1(0 \cdot 16) \dagger \\
0.77: 1(0 \cdot 17)^{*: *} \\
0 \cdot 72: 1(0 \cdot 18)^{* * *} \\
0.61: 1(0 \cdot 13) \\
0.61: 1(0 \cdot 13) \\
0.50: 1(0 \cdot 11) \\
0.39: 1(0 \cdot 10)\end{array}$ & $\begin{array}{l}0.19(0.07) \\
0.15(0.06) \\
0.17(0.06) \\
0.29(0.18) \\
0.39(0.18) \\
0.37(0.19) \\
0.40(0.24)\end{array}$ & $\begin{array}{r}6 \\
27 \\
44\end{array}$ & $\begin{array}{l}40 \cdot 3(5 \cdot 3) \\
27 \cdot 6(2 \cdot 5) \\
25 \cdot 4(5 \cdot 4)\end{array}$ & $\begin{array}{l}49 \cdot 4(9 \cdot 3) \\
56 \cdot 3(6 \cdot 4) \\
58 \cdot 8(9 \cdot 3)\end{array}$ & $\begin{array}{l}0.87: 1(0.20) \\
0.53: 1(0.07) \\
0.44: 1(0.09)\end{array}$ \\
\hline
\end{tabular}

$65.6(10.6)$

$0 \cdot 39: 1(0 \cdot 10)$

Comparing babies with respiratory distress with the healthy babies: fnot significant, ${ }^{*} p<0 \cdot 01,{ }^{*}{ }^{*} p<0 \cdot 005$.

$\mathrm{BP}=$ blood pressure; $\mathrm{RV}-\mathrm{RA}=$ maximal right ventricle to right atrial pressure difference.

$\mathrm{BP}=$ blood pressure, $\mathrm{RV}-\mathrm{R}=\mathrm{max}$ a in table 1. Systemic arterial pressure values are included from all babies examined, whether measurable tricuspid regurgitation was present or not. 
Table 3 Ductal patency and Doppler flow characteristics from 33 babies with hyaline membrane disease and 17 healthy preterm babies

\begin{tabular}{|c|c|c|c|c|c|c|c|c|c|c|c|}
\hline \multirow{2}{*}{$\begin{array}{l}\text { Age range } \\
\text { (hours) }\end{array}$} & \multicolumn{6}{|c|}{ Infants with respiratory distress } & \multicolumn{5}{|c|}{ Healthy preterm infants } \\
\hline & $\begin{array}{l}\text { Mean age } \\
\text { (hours) }\end{array}$ & $\begin{array}{l}\text { No } \\
\text { alive }\end{array}$ & $\begin{array}{l}\text { No } \\
\text { examined }\end{array}$ & $\begin{array}{l}\text { No (\%) with } \\
\text { bidirectional } \\
\text { flow }\end{array}$ & $\begin{array}{l}\text { No (\%) with } \\
\text { patent duct }\end{array}$ & $\begin{array}{l}\text { Maximum } \\
\text { Ao/Pa } \\
\text { pressure } \\
\text { difference } \\
\text { (mm Hg) }\end{array}$ & $\begin{array}{l}\text { Mean age } \\
\text { (hours) }\end{array}$ & $\begin{array}{l}\text { No } \\
\text { examined }\end{array}$ & $\begin{array}{l}\text { No (\%) with } \\
\text { bidirectional } \\
\text { flow }\end{array}$ & $\begin{array}{l}\text { No (\%) with } \\
\text { patent duct }\end{array}$ & $\begin{array}{l}\text { Maximum } \\
\text { Ao/Pa } \\
\text { pressure } \\
\text { difference } \\
\text { (mm } \mathrm{Hg})\end{array}$ \\
\hline $\begin{array}{l}0-12 \\
13-36 \\
37-72 \\
73-96 \\
97-144 \\
145-192 \\
193-240\end{array}$ & $\begin{array}{r}7 \\
23 \\
50 \\
84 \\
119 \\
169 \\
221\end{array}$ & $\begin{array}{l}33 \\
32 \\
32 \\
32 \\
32 \\
32 \\
31\end{array}$ & $\begin{array}{l}13 \\
30 \\
30 \\
25 \\
28 \\
17 \\
19\end{array}$ & $\begin{array}{l}11(85) \\
16(53)^{* * *} \\
9(30)^{*} \\
5(20) \\
2(7) \\
1(6) \\
1(5)\end{array}$ & $\begin{array}{l}33(100) \\
30(94)^{* * *} \\
28(88)^{*: *} \\
24(75)^{* * *} \\
17(53) \\
13(41) \\
8(26)\end{array}$ & $\begin{array}{l}5 \cdot 9(9 \cdot 2) \\
5 \cdot 6(4 \cdot 8)^{*}: \\
6 \cdot 9(6 \cdot 1)^{*} \\
10 \cdot 7(6 \cdot 9) \\
10 \cdot 0(7 \cdot 7) \\
16 \cdot 0(12 \cdot 2) \\
24 \cdot 1(16 \cdot 4)\end{array}$ & $\begin{array}{r}6 \\
27 \\
44 \\
88\end{array}$ & $\begin{array}{l}17 \\
17 \\
17 \\
17\end{array}$ & $\begin{array}{l}7(41) \\
0 \\
0 \\
n\end{array}$ & $\begin{array}{c}16(94) \\
8(47) \\
3(18) \\
1(6)\end{array}$ & $\begin{array}{l}9 \cdot 9(7 \cdot 5) \\
20 \cdot 5(4 \cdot 1) \\
30(6 \cdot 6) \\
-\end{array}$ \\
\hline
\end{tabular}

Comparing distressed with the healthy babies: ${ }^{*} \mathrm{p}<0.05,{ }^{* *}<0.0005$

If the arterial duct was closed at the final examination it was presumed to have remained closed.

Maximum $\mathrm{Ao} / \mathrm{Pa}$ pressure difference $=$ maximal pressure difference during the cardiac cycle between the aorta and pulmonary artery

analysis supports the use of a $5 \mathrm{~mm} \mathrm{Hg}$ constant for right atrial pressure. Therefore, for the rest of the analysis, this constant has been added when determining systolic pulmonary arterial pressure during the time period for which the babies were ventilated. The results are summarised in table 4.

\section{FACTORS INFLUENCING PULMONARY AND} SYSTEMIC ARTERIAL PRESSURE

Multiple linear regression analysis was performed to determine which factors most influenced systemic and pulmonary arterial pressures and their ratio. If a baby had more than one measurement within a single time band, one value was selected for analysis at random (this process was utilised for all the comparative analyses reported in this paper). The predictive factors tested in the analysis were: age, a:A oxygen tension ratio, inspired oxygen fraction, mean airway pressure, transcutaneous oxygen tension, and $\mathrm{pH}$ and carbon dioxide tension $\left(\mathrm{PCO}_{2}\right)$ from the most recent blood gas.

\section{Pulmonary:systemic arterial pressure ratio}

The regression model only explained $48 \%$ of the variability of the pulmonary:systemic arterial pressure ratio. Clearly factors other than those included in the analysis were influencing the ratio, including random variation. There was some evidence of a negative correlation with inspired oxygen fraction and a positive correlation with $\mathrm{PCO}_{2}$. However, the most significant correlation was with age (negative) and with mean airway pressure (positive). Therefore the downward trend in the pulmonary:systemic

Table 4 Corrected estimates of systolic pulmonary arterial pressure in babies with hyaline membrane disease. Results are mean $(S D)$

\begin{tabular}{lll}
\hline $\begin{array}{l}\text { Age } \\
\text { (hours) }\end{array}$ & $\begin{array}{l}\text { Systolic } \\
\text { pulmonary } \\
\text { arterial pressure } \\
(m m ~ H g)\end{array}$ & $\begin{array}{l}\text { Pulmonary:systemic } \\
\text { arterial pressure } \\
\text { ratio }\end{array}$ \\
\hline $0-12$ & $42 \cdot 4(9 \cdot 2)$ & $0 \cdot 86(0 \cdot 16)$ \\
$13-36$ & $40 \cdot 2(7 \cdot 1)$ & $0 \cdot 86(0 \cdot 18)$ \\
$37-72$ & $40 \cdot 2(7 \cdot 3)$ & $0 \cdot 82(0 \cdot 19)$ \\
$73-96$ & $39 \cdot 3(8 \cdot 9)$ & $0 \cdot 69(0 \cdot 13)$ \\
$97-144$ & $39 \cdot 1(6 \cdot 2)$ & $0 \cdot 69(0 \cdot 14)$ \\
$145-192$ & $34 \cdot 7(5 \cdot 2)$ & $0 \cdot 53(0 \cdot 12)$ \\
$193-240$ & $29 \cdot 1(6 \cdot 1)$ & $0 \cdot 43(0 \cdot 11)$
\end{tabular}

Data as in table 2, after allowing for an average right atrial pressure of $5 \mathrm{~mm} \mathrm{Hg}$ in babies ventilated at the time of examination. arterial pressure ratio persisted with increasing age even with continuing severe respiratory distress. A higher mean airway pressure was associated with a higher pulmonary:systemic arterial pressure ratio. This relationship was mediated by low systemic arterial pressure and not high pulmonary arterial pressure.

\section{Systemic arterial pressure}

Systemic arterial pressure correlated negatively with mean airway pressure and positively with age.

\section{Pulmonary arterial pressure}

The regression model explained less than $20 \%$ of the variability of pulmonary arterial pressure. There was a strong negative correlation with age, and a weaker correlation with $\mathrm{PCO}_{2}$.

None of these variables correlated with the a:A oxygen tension ratio.

Utilising the serial measurements to determine the effect of disease severity, paired $t$ tests were done comparing the final low value for the arterial pressure ratio with the immediate previous higher value in each baby. There was no consistent correlation with a fall in the ratio with any of the selected predictive factors.

\section{INDIVIDUAL VARIABILITY}

Serial values for the pulmonary:systemic arterial pressure ratio for the whole group are plotted in fig $2 \mathrm{~A}$. All the babies with hyaline membrane disease in whom three or more measurements were obtained are shown. The figure demonstrates considerable variability and a downward trend with age. In fig $2 \mathrm{~B}$ the values derived from the healthy babies are superimposed, showing the dramatic difference between the groups despite this variability.

Examination of the serial plot (fig 2A) shows six babies with a sharp rise in the ratio at around 48 hours of age against the trend of the whole group. These are highlighted in fig 2C. Two babies, represented by the open symbols, were remarkable in having a very low ratio initially, accompanied by pure left to right ductal flow, then rising to a much higher value with bidirectional ductal flow. They were two mature babies ( 34 and 37 weeks' gestation) who were initially unventilated with relatively mild hyaline 
membrane disease. They both developed worsening respiratory distress, requiring a brief period of ventilation on days three and four. The three highest values in fig $2 \mathrm{C}$ were associated with systemic hypotension: two, as indicated, after a recently treated pneumothorax and the third with myocardial dysfunction secondary to myocardial ischaemia. The sixth baby was the 39 week gestation baby, who was thought clinically to have an element of persistent fetal circulation, and was receiving inotropic support. In these six cases the pulmonary:systemic

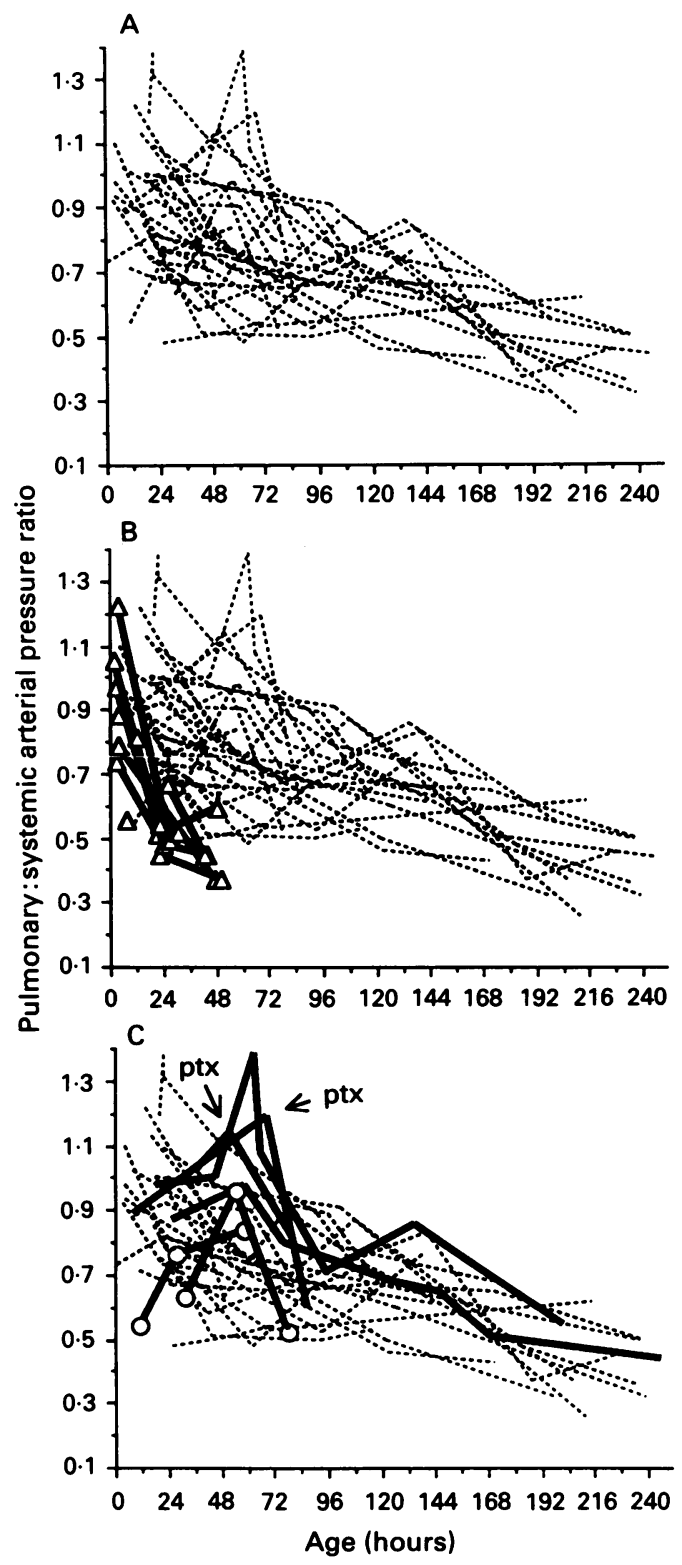

Figure 2 Serial measurements of the pulmonary:systemic arterial pressure ratio in babies with hyaline membrane disease. Systolic pulmonary arterial pressure is derived from maximal tricuspid regurgitant velocity (adding $5 \mathrm{~mm} \mathrm{Hg}$ for right atrial pressure in ventilated babies). Only babies with three or more values are included. Points of measurement are excluded for clarity but are indicated by angulation changes. (A) The whole group with hyaline membrane disease. The (A) The whole group with hyaline membrane disease. The
ratios show considerable variability and a downward trend with age. $(B)$ All the values from the healthy preterm babies (open triangles, dark lines) are superimposed on those from the babies with hyaline membrane disease. The rate of fall in the pulmonary to systemic arterial pressure ratio is much faster in the healthy babies. $(C)$ In six babies with hyaline membrane disease, the ratio rose between the second and third day of life, against the trend (see text); ptx, recent pneumothorax. arterial pressure ratio was closely related to oxygen requirements.

Two other babies (of 32 and 36 weeks' gestation) were also unventilated until the third day but had high initial pulmonary arterial pressure values. In one of these babies the pressure value fell soon after ventilation was started while in the other it did not.

One baby (36 weeks' gestation, $2760 \mathrm{~g}$ ) received tolazoline at 22 hours of age. Arterial $\mathrm{pH}$ was $7 \cdot 34$ and $\mathrm{PCO}_{2} 6 \cdot 1 \mathrm{kPa}$. Arterial oxygen saturation rose from $78 \%$ to $90 \%$. Derived pulmonary arterial systolic pressure was $66 \mathrm{~mm}$ $\mathrm{Hg}$ and fell only marginally, to $60 \mathrm{~mm} \mathrm{Hg}$. The pulmonary:systemic arterial pressure ratio was raised $(1 \cdot 4: 1)$, and is the earliest peak in fig $3 \mathrm{~A}$; the ratio had risen from 1-2:1 over the two hours before treatment.

After 48 hours, no babies with uncomplicated hyaline membrane disease (that is, no pneumothorax or myocardial dysfunction) had a pulmonary:systemic arterial pressure ratio over $1 \cdot 0: 1$.

\section{GESTATIONAL AGE}

Using the arterial pressure ratio, rather than pulmonary arterial pressure alone, it was possible to compare babies of differing size and maturity directly. Babies of less than 30 weeks' gestation (mean 27.6) were compared with those of over 32 weeks' gestation (mean $35 \cdot 7$ ). The serial values are plotted in fig 3 . The course over time is very varied among the larger babies, but remarkably consistent in the more premature babies. As the ratio may be transiently raised by pneumothorax, these values were excluded

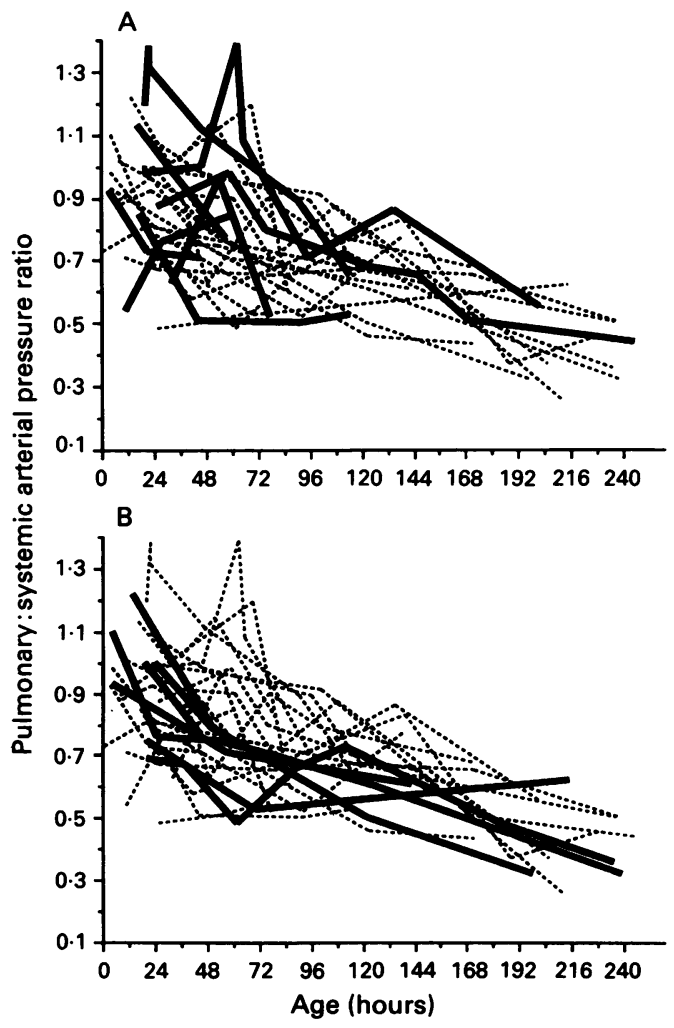

Figure 3 A comparison of the way the ratio of

pulmonary:systemic arterial pressure ratio changed with time $(A)$ in eight babies $>32$ weeks' gestation and $(B)$ seven babies $<30$ weeks' gestation. 
Table 5 A comparison of systemic and pulmonary arterial systolic pressure in infants of less than 30 weeks' gestation with infants of over 32 weeks' gestation when 13-36 hours and 37-72 hours old. Results are mean (SD)

\begin{tabular}{|c|c|c|c|c|}
\hline & \multicolumn{2}{|c|}{$<30$ weeks' gestation } & \multicolumn{2}{|c|}{$>32$ weeks' gestation } \\
\hline & 13-36 hours & $37-72$ hours & 13-36 hours & $37-72$ hours \\
\hline $\begin{array}{l}\text { No of observations } \\
\text { Systemic arterial pressure (mm } \mathrm{Hg}) \\
\text { Pulmonary arterial pressure (mm Hg) } \\
\text { Pulmonary:systemic arterial pressure ratio } \\
\text { Fractional inspiratory oxygen } \\
\text { a:A ratio }\end{array}$ & $\begin{array}{l}11 \\
44 \cdot 8(7 \cdot 6) \\
37 \cdot 0(6 \cdot 1)^{*} \\
0 \cdot 83: 1(0 \cdot 20) \\
0 \cdot 65(0 \cdot 19) \\
0 \cdot 15(0 \cdot 03)\end{array}$ & $\begin{array}{l}9 \\
51 \cdot 3(8 \cdot 7) \\
36 \cdot 0(6 \cdot 4): \\
0 \cdot 70: 1(0 \cdot 11) \\
0 \cdot 59(0 \cdot 19) \\
0 \cdot 19(0 \cdot 08)\end{array}$ & $\begin{array}{l}8 \\
50 \cdot 3(7 \cdot 3) \\
44 \cdot 1(7 \cdot 8) \\
0 \cdot 88: 1(0 \cdot 20) \\
0 \cdot 63(0 \cdot 14) \\
0 \cdot 18(0 \cdot 06)\end{array}$ & $\begin{array}{l}9 \\
53 \cdot 0(8 \cdot 5) \\
46 \cdot 6(5 \cdot 1) \\
0 \cdot 88: 1(0 \cdot 20) \\
0 \cdot 68(0 \cdot 19) \\
0 \cdot 14(0 \cdot 02)\end{array}$ \\
\hline
\end{tabular}

from the comparison presented here and in table 5. Pulmonary arterial pressure is significantly lower in the babies of lower gestation. The pulmonary:systemic arterial pressure ratio is initially similar, but is significantly lower in the more premature babies at 37-72 hours; this is due mostly to their larger rise in systemic arterial pressure between the two time periods.

There were no significant differences in the a:A oxygen tension ratio or inspired oxygen concentrations between the two groups. However, these are small numbers and it may be important that these figures show a trend suggesting that the more mature babies had worsening respiratory distress between the first and second age band.

\section{Discussion}

These two methods of assessing pulmonary arterial pressure are new to neonatology, so are the results reliable? It is possible to underestimate peak flow velocities if the Doppler probe is not directly in line with flow, so while overestimation is unlikely, some of the values could have underestimated the true pressure, although this was not a problem in validatory studies. $^{4-8}$ Furthermore, when ductal flow patterns were compared with the derived pulmonary:systemic arterial pressure ratio in our previous, report of healthy babies over the first three days of life, ${ }^{9}$ bidirectional flow was associated with a ratio of between $0.88: 1$ and 1.22:1 (mean 0.96:1), which would not suggest serious underestimation of pulmonary arterial pressure. Musewe et al found that, in neonates with respiratory distress, an allowance of $10 \mathrm{~mm} \mathrm{Hg}$ for right atrial pressure improved the correlation of pulmonary arterial systolic pressure values obtained simultaneously from tricuspid regurgitation and from ductal flow. ${ }^{15}$ Ten $\mathrm{mm} \mathrm{Hg}$ may be appropriate in large babies with asphyxia or persistent fetal circulation, but seems too high for a preterm neonate with hyaline membrane disease. ${ }^{12}$ This high figure may therefore represent a tendency for the tricuspid regurgitant technique to underestimate pulmonary arterial pressure in the premature neonate. This is partly supported by the observation that some babies in the present study had bidirectional ductal flow with pulmonary:systemic arterial pressure ratio below $0 \cdot 8: 1$, even allowing $5 \mathrm{~mm} \mathrm{Hg}$ for right atrial pressure. It is, however, equally possible that the ductal flow method may slightly overestimate pulmonary arterial pressure. It would seem prudent therefore to combine these two methods where this is possible and our conclusions are drawn using both of the methods. In observing trends within a subject, the allowance for right atrial pressure is less important, as this will change much less than arterial pressure.

The most striking feature in this study is the appreciable difference between the healthy preterm babies and those with respiratory distress. Pulmonary hypertension is indeed a significant part of hyaline membrane disease. This finding is consistent with those of Halliday et $a l^{16}$ and Evans and Archer $^{17}$ who used systolic time intervals to estimate pulmonary arterial pressure in hyaline membrane disease. The present study has shown that there is a delay in the normal postnatal fall in pulmonary arterial pressure and the normal postnatal rise in systemic blood pressure. This is accompanied by persistent patency of the arterial duct. Even when the respiratory distress remains severe, the pulmonary:systemic arterial pressure ratio usually continues to fall, though at a much slower rate than in the healthy baby.

In contrast with Halliday et al, our study and that of Evans and Archer, found no consistent relationship with disease severity, although there was a suggestion in our study that arterial carbon dioxide tension was important and in the study of Evans and Archer that $\mathrm{pH}$ had an influence. Oxygen concentrations in the pulmonary artery may also have influenced pulmonary arterial pressure because oxygen is known to be a potent pulmonary vasodilator. ${ }^{18} 19$ Oxygen saturation concentrations varied only over a fairly narrow range in most of the babies reported here, but the concentrations were almost always lower than those seen in the healthy preterm neonate. ${ }^{20}$ It would be necessary to undertake serial studies in individual babies, while varying oxygen saturation over a wider range, to demonstrate how much influence hypoxia had on the persistent pulmonary hypertension. Such a study was done by Halliday et al using $\mathbf{M}$ mode echocardiography in babies with bronchopulmonary dysplasia. ${ }^{21}$

The negative influence of mean airway pressure on systemic blood pressure was independent of disease severity and is presumably related to high intrathoracic pressure impeding venous return and thereby reducing cardiac output. $^{22}{ }^{23}$ The high pulmonary:systemic arterial pressure ratio is thus partly maintained by ventilation itself.

There was considerable temporal variability in both arterial pressures, and pneumothorax had a profound impact. It also appears that gestation is an important factor. Less mature 
babies had lower absolute pulmonary arterial pressures and a steadier fall in the pulmonary: systemic arterial pressure ratio over time. This latter feature may be a chance finding, because of the small sample size, or it could be due to a genuine difference in the disease at different gestations or to management differences. In the classical disease there is steadily worsening respiratory distress over the first two to three days, followed by steady improvement. This was seen in the four relatively mature babies who were not ventilated until they were about 48 hours old. In three of these babies pulmonary arterial pressure fell soon after ventilation, suggesting that it was higher at a time of alveolar collapse. The less mature babies were all ventilated early, and structural lung immaturity may be a further important ingredient of the disease in these babies.

A spectrum of maladaptation of the transitional circulation to extrauterine life was described by Reimenschneider $e t$ al who presented 13 newborn babies who were cyanosed in oxygen without structural heart disease. ${ }^{24}$ There were three categories: pulmonary hypertension with normal myocardial function and blood pressure, pulmonary hypertension with decreased myocardial function, and systemic hypotension alone without appreciable pulmonary hypertension. The present study suggests that these circulatory disturbances can also occur without overt cyanosis and can be part of hyaline membrane disease (though they will not usually present as a clinical problem). The observation that babies can be clinically stable and acyanotic with pulmonary arterial pressure at sytemic levels and a patent duct suggests that despite pulmonary hypertension, pulmonary blood flow is adequate. This distinction is important; merely having pulmonary hypertension does not imply that it should be treated pharmacologically. Indeed, drugs such as tolazoline and prostacyclin may cause systemic hypotension, ${ }^{25}$ already a common accompaniment of severe hyaline membrane disease, ${ }^{26}$ and therefore cause clinical deterioration.

The present analysis has concentrated on the pressure ratios seen in systole, but pure right to left ductal shunting was never seen in any of the children in this study. Therefore it can be inferred that, during diastole (which is longer than systole), pressure in the pulmonary artery was always lower than systemic pressure, allowing a period of left to right flow with each cardiac cycle. Furthermore, it is probable that right to left shunting across the foramen ovale is at least as important in the development of persistent fetal circulation, ${ }^{27}$ and in this context, right ventricular diastolic dysfunction may be as important as pulmonary arterial pressure. The method used by Halliday et al to estimate pulmonary arterial pressure is influenced by right ventricular dysfunction, ${ }^{16}$ and this might explain why their values followed the severity of hyaline membrane disease more closely.

We conclude that there is a spectrum of postnatal circulatory adaptation among babies with hyaline membrane disease. At one extreme there are babies in whom the pulmonary: systemic arterial pressure ratio is always relatively low, even with severe disease. At the other extreme there are babies who have appreciable pulmonary hypertension, some of whom have problems related to persistent fetal circulation, even with relatively mild disease, and some of whom do not. The uniting feature of all of these babies with hyaline membrane disease is that postnatal circulatory adaptation is delayed.

Dr Skinner is research fellow in child health supported by the National Heart Research Fund. Doppler machinery was funded by Children in Need. We thank Dr Milligan for his support and we are most grateful for the kind cooperation of the babies' parents and the neonatal nursing and medical staff at the Newcastle General and Princess Mary Maternity hospitals.

1 Moss AJ, Emmanouilides GC, Rettori O, Higashino SM, Adams FH. Postnatal circulatory and metabolic adjustments in normal and distressed premature infants. Biol Neonate 1965;8:177-97.

2 Chu J, Clements JA, Cotton EK, Klaus MH, Sweet AY, Tooley WH. Neonatal pulmonary ischaemia. Part 1: clinical and physiological studies. Pediatrics 1967;40. 709-82.

3 Avery ME, Mead J. Surface properties in relation to atelectasis and hyaline membrane disease. Am $\mathcal{F}$ Dis Child 1959;97:517-23.

4 Yock PG, Popp RL. Noninvasive estimation of right ventricular systolic pressure by Doppler ultrasound in patients with tricuspid regurgitation. Circulation 1984;70: 657-62.

5 Berger M, Haimowitz A, Van Tosh A, Berdoff RL, Goldberg $\mathrm{E}$. Quantitative assessment of pulmonary hypertension in patients with tricuspid regurgitation using continuous wave Doppler ultrasound. $\mathcal{F}$ Am Coll Cardiol 1985;6: w59-65.

6 Currie PJ, Seward JB, Chan K, et al. Continuous wave Doppler determination of right ventricular pressure: Doppler determination of right ventricular pressure: a
simultaneous Doppler-catheterisation study in 127 patients. Simultaneous Doppler-catheterisa

7 Skjaerpe T, Hatle L. Noninvasive estimation of systolic pressure in the right ventricle in patients with tricuspid regurgitation. Eur Heart $\mathcal{F}$ 1986;7:704-10.

8 Vazquez de Prada JA, Ruano J, Martin-Duran R, et al. Noninvasive determination of pulmonary arterial systolic pressure by continuous wave Doppler. Int $\mathcal{f}$ Cardiol 1987;16:177-84.

9 Skinner JR, Boys RJ, Hunter S, Hey EN. Non-invasive assessment of pulmonary arterial pressure in healthy neonates. Arch Dis Child 1991;66:386-90.

10 Tarnow-Mordi W, Ogston S, Wilkinson AR, et al. Predicting death from initial disease severity in very low birthweight infants: a method for comparing the performance of infants: a method for comparing the
neonatal units. $B M \mathcal{f}$ 1990;300:1611-4.

11 Hatle L, Angelsen B, eds. Physics of blood flow. Doppler ultrasound in cardiology. Philadelphia: Lea and Febiger, ultrasound

12 Skinner JR, Milligan DWA, Hunter AS, Hey EN. Central venous pressure in the ventilated neonate. Arch Dis Child 1992;67:374-7.

13 Musewe NN, Poppe D, Smallhorn JF, et al. Validation of Doppler-derived pulmonary arterial pressure in patients with ductus arteriosus under different haemodynamic states. Circulation 1987;76:1081-91.

14 Houston AB, Lim MK, Doig WB, et al. Doppler flow characteristics in the assessment of pulmonary artery pressure in ductus arteriosus. Br Heart $\mathcal{F}$ 1989;62:284-90.

15 Musewe NN, Poppe D, Smallhorn JF, et al. Doppler echocardiographic measurement of pulmonary artery presColl Cardiol 1990;15:446-56.

16 Halliday H, Hirschfeld S, Riggs T, Liebman J, Fanaroff A Bormuth C. Respiratory distress syndrome: echocardiographic assessment of cardiovascular function and pulgraphic assessment of cardiovascular function and
monary vascular resistance. Pediatrics 1977;60:444-9.

17 Evans NJ, Archer LNJ. Doppler assessment of pulmonary artery pressure and extrapulmonary shunting in the acute phase of hyaline membrane disease. Arch Dis Child 1991;66:6-11.

18 Dawes GS. The pulmonary circulation in the foetus and newborn. In: Dawes GS, ed. Foetal and neonatal physiology. Chicago: Year Book Medical Publishers, 1968:79-90.

19 Peckham GJ, Fox WW. Physiologic factors affecting pulmonary artery pressure in infants with persistent pulmonary hypertension. F Pediatr 1978;93:1005-10.

20 Poets CF, Stebbens VA, Alexander JR, Arrowsmith WA Salfield SAW, Southall DP. Oxygen saturation and breathing patterns in infancy. 2: Preterm infants at discharge from special care. Arch Dis Child 1991;66:574-8.

21 Halliday $\mathbf{H}$, Dumpet $F$, Brady J. Effects of inspired oxygen on echocardiographic assessment of pulmonary vascula resistance and myocardial contractility in bronchopulmonary dysplasia. Pediatrics 1980;65:536-40.

22 Maayan C, Eyal F, Mandelberg A, Sapoznikov D, Lewis BS Effect of mechanical ventilation and volume loading on left ventricular performance in premature neonates with ventricular performance in premature neonat 1986;14 858-60. 
23 Furzan JA, Gabriele G, Wheeler JM, Fixler DE, Rosenfeld CR. Regional blood flows in newborn lambs during endotracheal continuous airway pressure and continuous negative pressure breathing. Pediatr Res 1981;15:874-8.

24 Reimenschneider TA Nielsen HC, Ruttenberg HD, Jaff RB. Disturbances of the transitional circulation: spectrum of pulmonary hypertension and myocardial dysfunction. f Pediatr 1976;4:622-5.
25 McIntosh N, Walters RO. Effect of tolazoline in severe hyaline membrane disease. Arch Dis Child 1979;54:105-10. 26 Stahlman M, Blankenship WJ, Shepard FM, Gray J, Young WC, Malan AF. Circulatory studies in clinical hyaline membrane disease. Biol Neonate 1972;20:300-20

27 Gersony WM. Neonatal pulmonary hypertension: pathophysiology, classification and etiology. Clin Perinatol 1984; 11:517-24. 